\title{
Uso de fosfato natural Gafsa e cama de aviário em sistema orgânico de produção de batata
}

\author{
Use of Gafsa rock phosphate and poultry litter in organic system of potato production
}

\section{Gilberto Nava}

Recebido em 09/03/2016 / Aceito em 16/11/2016

\section{RESUMO}

O trabalho foi realizado no município de São Joaquim, Santa Catarina, durante o ciclo de cultivo 2009/2010, com o objetivo de avaliar a utilização fosfato natural Gafsa combinado com cama de aviário sobre a produtividade de tubérculos e a composição mineral das folhas em um sistema orgânico de produção de batata consumo. $\mathrm{O}$ delineamento experimental foi o de blocos ao acaso com cinco repetições e foram testadas quatro doses de fosfato natural Gafsa $(0$, 1333,2666 e $4000 \mathrm{~kg} \mathrm{ha}^{-1}$ ) combinadas à dose única de $8 \mathrm{t} \mathrm{ha}^{-1}$ de cama de aviário. Independentemente da dose utilizada, não houve incremento na produção de tubérculos de batata com a adição de fosfato natural Gafsa. A produtividade obtida mesmo com a dose máxima do fosfato natural foi igual em relação a quando se adubou somente com cama de aviário, indicando que a solubilização do fosfato natural Gafsa foi baixa durante um único ciclo de produção da batata. A dose de $8 \mathrm{t} \mathrm{ha}^{-1}$ de cama de aviário propiciou concentrações adequadas dos nutrientes nas folhas, exceto para $\mathrm{P}$ e $\mathrm{Ca}$. Devido à baixa concentração de $\mathrm{P}$ encontrada nas folhas, presume-se que este nutriente foi o que mais limitou o rendimento de tubérculos.

PALAVRAS-CHAVE: Solanum tuberosum, adubação orgânica, fósforo, fertilidade do solo, nutrição de plantas.

\section{ABSTRACT \\ This work was carried out in São Joaquim, Santa Catarina, Brazil, during the 2009/2010 crop cycle, in order to evaluate the use of Gafsa rock phosphate combined with poultry litter on tuber yield and leaf mineral composition of organically grown potatoes. The experimental design was a completely randomized block with five replications testing four}

rates of Gafsa rock phosphate $(0 ; 1.333 ; 2.666$ and $\left.4,000 \mathrm{~kg} \mathrm{ha}^{-1}\right)$ combined with the single application of $8 \mathrm{tha}^{-1}$ of poultry litter. Regardless of rate applied, the tuber production was not affected by rock phosphate fertilization. Even with the maximum rate of Gafsa rock phosphate, tuber yield was similar to the control with just poultry litter, indicating that the rock phosphate solubility was low during a single crop cycle. Except for $\mathrm{P}$ and $\mathrm{Ca}$ contents, the poultry litter rate of $8 \mathrm{tha}^{-1}$ promoted adequate concentrations for the other nutrients evaluated in the leaves. Due the low $\mathrm{P}$ content in the leaves, it was inferred that $\mathrm{P}$ was the main limiting nutrient for potato tuber yield in our study.

KEYWORDS: Solanum tuberosum, organic fertilization, phosphorus, soil fertility, plant nutrition.

\section{INTRODUÇÃO}

No cultivo convencional de batata normalmente utilizam-se grandes quantidades de fertilizantes minerais, o que pode gerar contaminação no ambiente, além de onerar demasiadamente os custos de produção, que somente com fertilizantes pode representar aproximadamente $13 \%$ do custo total (CEPEA 2016).

Os solos do planalto sul de Santa Catarina caracterizam-se principalmente pela elevada acidez e baixos teores de fósforo (P) disponível, o que torna necessária a aplicação de quantidades elevadas do fertilizante. No sistema convencional de produção, o $P$ é o nutriente que mais limita a produtividade da batata (NAVA et al. 2007, LUZ et al. 2013). O P aumenta o tamanho e o peso específico dos tubérculos (ROSEN et al. 2014, FERNANDES et al. 2015a e 2015b), favorecendo a obtenção de tubérculos maiores, com maior aceitação pelo consumidor.

Empresa Brasileira de Pesquisa Agropecuária, Pelotas, RS, Brasil.

Autor para correspondência < gilberto.nava@embrapa.br> 
O cultivo orgânico, em que se substituem fertilizantes minerais e agrotóxicos por adubação orgânica e manejo diferenciado, tem surgido como uma alternativa de manejo sustentável e de renda aos produtores rurais. Neste sistema, a fertilização é baseada no uso de estercos, fertilizantes minerais naturais pouco solúveis como os fosfatos naturais e adubação verde. A combinação destas práticas pode trazer efeitos ainda melhores sobre o rendimento das culturas (SILVA et al. 2007).

Face à alta exigência da cultura, o uso de fontes alternativas de fertilizantes com comprovada eficiência agronômica, principalmente que contenham $\mathrm{P}$, é fundamental para a obtenção de produções econômicas na produção orgânica de batata, uma vez que não é permitido o uso de fertilizantes solúveis neste sistema. Os fosfatos de origem sedimentar, também conhecidos como fosfatos naturais reativos, a exemplo do Gafsa, apresentam maior solubilidade do que os fosfatos naturais de origem ígnea (CORREA et al. 2005) e por isso geralmente apresentam maior eficiência agronômica. Além da origem, a eficiência dos fosfatos naturais está relacionada principalmente com o pH do solo, tamanho das partículas e o modo de aplicação. A diminuição do $\mathrm{pH}$ favorece a liberação de prótons (íons $\mathrm{H}^{+}$) que auxiliam no rompimento das estruturas da apatita, favorecendo a liberação do P. Portanto, a velocidade de dissolução dos fosfatos naturais é inversamente proporcional ao $\mathrm{pH}$ do solo (HOROWITZ \& MEURER 2004).

Uma vez que possuem baixa solubilidade em água, quanto menor o tamanho das partículas, maior será a liberação de P. HOROWITZ \& MEURER (2003), trabalhando em dois ciclos sucessivos com plantas de milho, observaram que os fosfatos naturais finamente moídos (partículas $<0,074 \mathrm{~mm}$ ) produziram resultados semelhantes, no primeiro cultivo, aos obtidos com a aplicação do superfosfato triplo granulado, enquanto que aqueles com partículas maiores do que $0,297 \mathrm{~mm}$ produziram resultados próximos ou semelhantes aos da testemunha, sem qualquer aplicação de P.

O maior contato do fosfato natural com o solo também favorece sua dissolução. OLIVEIRA JUNIOR et al. (2008) observaram que a eficiência agronômica do fosfato natural reativo Arad aplicado a lanço para a cultura da soja foi superior à verificada com a aplicação desta mesma fonte no sulco de semeadura. FRANZINI et al. (2009) também observaram que $\mathrm{o}$ aproveitamento do $\mathrm{P}$ do fosfato natural reativo de
Gafsa pelas plantas de milho e de soja foi maior quando o fertilizante foi aplicado de forma não localizada, o que contribui significativamente para aumentar a área de contato e a consequente dissolução do fertilizante.

Devido à grande oferta de resíduos oriundos dos criatórios de aves nas diversas regiões do estado de Santa Catarina, a cama de aviário surge como uma boa alternativa para o suprimento de N, P e K. Além de fornecer nutrientes, a cama de aviário pode melhorar os atributos físicos do solo (ESPANHOL et al. 2007, VALADÃO et al. 2011), atuando também como condicionador de solo. Uma das vantagens do uso do adubo orgânico é a liberação de $\mathrm{P}$ mais lenta e sincronizada às necessidades da planta quando comparada ao uso de adubo solúvel, o que reduz a adsorção deste nutriente pelas partículas reativas do solo. A mineralização do adubo orgânico, além de liberar $\mathrm{P}$ inorgânico que pode ser absorvido pelas plantas quando na solução, também produz substâncias húmicas que competem pelos grupos funcionais de partículas reativas com o íon fosfato (SIQUEIRA et al. 2004)

O presente trabalho teve por objetivo avaliar a utilização fosfato natural Gafsa combinado com cama de aviário sobre a produtividade de tubérculos e a composição mineral das folhas em um sistema orgânico de produção de batata consumo.

\section{MATERIAL E MÉTODOS}

O experimento foi realizado no município de São Joaquim, SC (2817'25' 'S, 4956'56”'W) durante a safra de 2009/2010, sobre um Cambissolo Húmico (SANTOS et al. 2013). Um mês antes do plantio aplicou-se 3,0 t ha ${ }^{-1}$ de calcário dolomítico, com PRNT de 75\%, incorporando-se o mesmo por meio de aração e gradagem. Por ocasião do plantio efetuou-se outra gradagem e o sulcamento da área experimental.

Análises químico-físicas, realizadas antes do plantio, revelaram os seguintes resultados: $\mathrm{pH}$ em água de 5,1;6,0 $\mathrm{mg} \mathrm{dm}^{-3}$ de $\mathrm{P}$ extraível por Mehlich 1; 4,7 $\mathrm{mmol}_{\mathrm{c}} \mathrm{dm}^{-3}$ de $\mathrm{K} ; 34 \mathrm{mmol}_{\mathrm{c}} \mathrm{dm}^{-3}$ de $\mathrm{Ca} ; 23$ mmol $_{\mathrm{c}} \mathrm{dm}^{-3}$ de $\mathrm{Mg} ; 52 \mathrm{~g} \mathrm{dm}^{-3}$ de matéria orgânica e $260 \mathrm{~g} \mathrm{dm}^{-3}$ de argila. Para este tipo de solo o teor de $6,0 \mathrm{mg} \mathrm{dm}^{-3}$ de $\mathrm{P}$ é considerado como muito baixo, sendo recomendado para esta situação $395 \mathrm{~kg} \mathrm{ha}^{-1}$ para uma expectativa de rendimento inferior a $30 \mathrm{t}$ ha $^{-1}$ de tubérculos (CQFS-RS/SC 2016).

O delineamento experimental foi de blocos ao acaso, com cinco repetições e quatro tratamentos: T1 
$-4000 \mathrm{~kg} \mathrm{ha}^{-1}$ de fosfato natural Gafsa $+8 \mathrm{t} \mathrm{ha}^{-1}$ de cama de aviário; T2 - $2666 \mathrm{~kg} \mathrm{ha}^{-1}$ de fosfato natural Gafsa +8 t ha $^{-1}$ de cama de aviário; T3 - $1333 \mathrm{~kg}$ $\mathrm{ha}^{-1}$ de fosfato natural Gafsa $+8 \mathrm{t} \mathrm{ha}^{-1}$ de cama de aviário; $\mathrm{T} 4-8 \mathrm{t} \mathrm{ha}^{-1}$ de cama de aviário e zero $\mathrm{kg}$ $\mathrm{ha}^{-1}$ de fosfato natural Gafsa. Na composição da cama de aviário havia 23,4 $\mathrm{g} \mathrm{kg}^{-1}$ de $\mathrm{N}, 27,3 \mathrm{~g} \mathrm{~kg}^{-1}$ de $\mathrm{P}$ e 21,9 $\mathrm{g} \mathrm{kg}^{-1}$ de $\mathrm{K}$. A dose de $8 \mathrm{t}$ de cama de aviário corresponde à adição de aproximadamente $490 \mathrm{~kg} \mathrm{ha}^{-1}$ de $\mathrm{P}_{2} \mathrm{O}_{5}$. O fosfato natural Gafsa foi aplicado na forma de farelo e possuía $28 \%$ de $\mathrm{P}_{2} \mathrm{O}_{5}$ total e $10 \%$ de $\mathrm{P}_{2} \mathrm{O}_{5}$ solúvel em ácido cítrico a $2 \%$.

As unidades experimentais foram compostas por quatro fileiras com 20 plantas cada, sendo avaliadas somente as duas centrais como úteis e um total de 40 plantas. O espaçamento de plantio foi de $80 \mathrm{~cm}$ entre filas e $20 \mathrm{~cm}$ entre plantas. Os fertilizantes foram aplicados integralmente no plantio, tomandose o cuidado de incorporar o esterco e o fosfato na camada de aproximadamente $5,0 \mathrm{~cm}$ do sulco de plantio.

O plantio foi realizado no dia 15 de dezembro de 2009, utilizando-se tubérculos-semente do tipo III (MAPA 1987), cultivar "catucha", cujo diâmetro transversal variou entre 30 a $40 \mathrm{~mm}$. A cobertura dos tubérculos foi efetuada manualmente, com auxílio de enxadas. Após a emergência, as plantas receberam controle fitossanitário, semelhante ao adotado pelos produtores orgânicos de batata da região de São Joaquim. Durante o ciclo da cultura não foi necessária a realização de irrigação uma vez que houve uma boa distribuição de chuvas durante o período (Figura 1).

$\mathrm{Na}$ época da floração foram coletadas amostras de 20 folhas por parcela (uma por planta), sempre se amostrando a quarta folha a partir do ápice da planta. As amostras foram secadas em estufa a $65{ }^{\circ} \mathrm{C}$ e moídas. Uma subamostra de $0,5 \mathrm{~g}$ do material moído foi submetida à digestão ácida nitroperclórica com $\mathrm{HClO}_{4}(1,0 \mathrm{~mL})+\mathrm{HNO}_{3}(6,0 \mathrm{~mL})$ a $190{ }^{\circ} \mathrm{C}$ em bloco digestor por aproximadamente 2 horas. No extrato, determinaram-se as concentrações de $\mathrm{P}$ por espectrofotometria UV (método vanadato-molibdato) e $\mathrm{K}, \mathrm{Ca}, \mathrm{Mg}, \mathrm{Fe}, \mathrm{Mn}$ e $\mathrm{Zn}$ por espectrometria de absorção atômica em chama. Determinou-se B pelo método de azometina $\mathrm{H}$, após incineração de $0,3 \mathrm{~g}$ em forno mufla a $550{ }^{\circ} \mathrm{C}$ por 2 horas. $\mathrm{O} \mathrm{N}$ foi determinado pelo método micro-Kjeldahl, após a digestão de $0,2 \mathrm{~g}$ com $\mathrm{H}_{2} \mathrm{O}_{2}(2,0 \mathrm{~mL})+\mathrm{H}_{2} \mathrm{SO}_{4}(5,0 \mathrm{~mL})$ e sais catalisadores a $380{ }^{\circ} \mathrm{C}$ até a completa digestão, caracterizada por um líquido incolor ou levemente esverdeado.

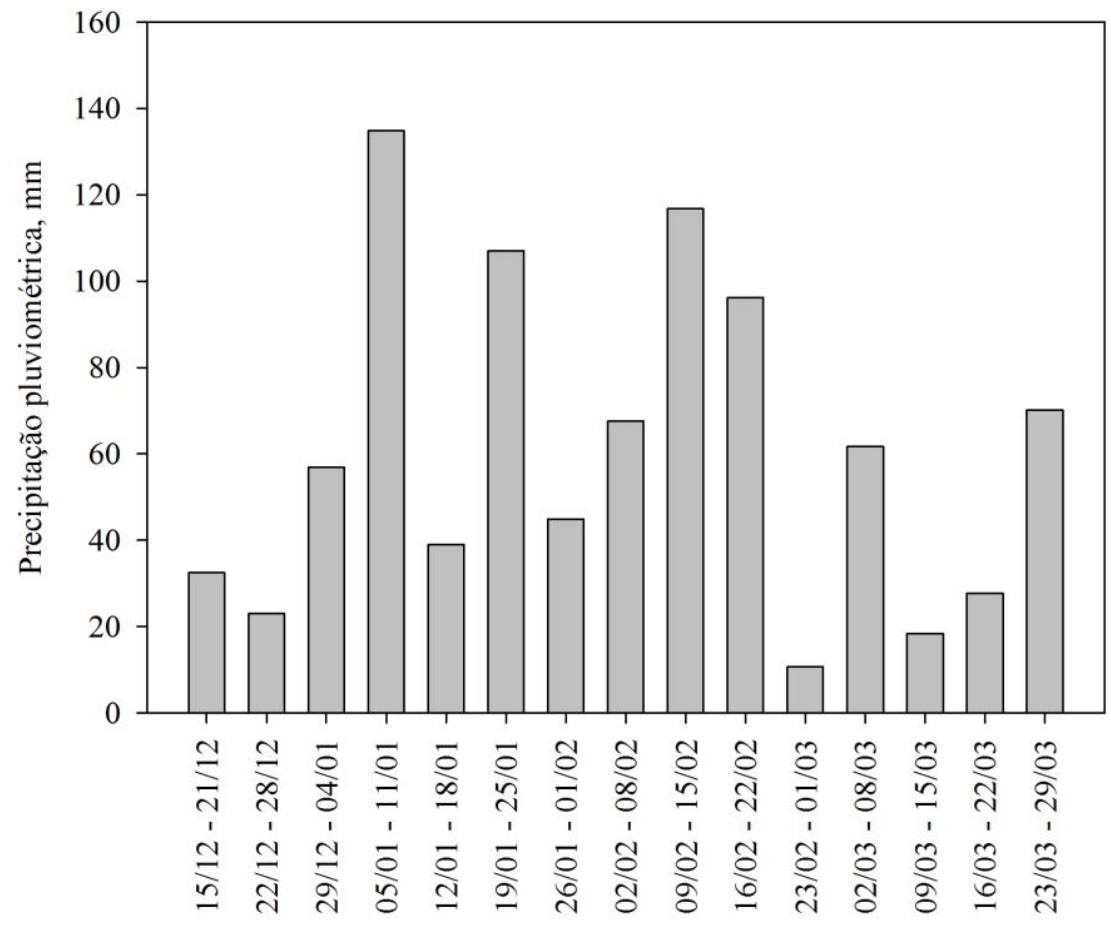

Figura 1 - Distribuição semanal da precipitação pluviométrica durante o período compreendido entre o plantio e a colheita da batata.

Figure 1 - Weekly distribution of rainfall during the period between planting and harvesting of the potato. 
Trinta dias após o plantio foi realizada a amontoa, com o auxílio de um arado aiveca de tração animal. A colheita foi realizada em 30/03/2010 e, posteriormente ao arranquio, os tubérculos foram transportados para a unidade de classificação, onde foram classificados, obtendo-se a massa (gramas) em cada peneira, seguindo as normas vigentes para a produção de batata consumo do estado de Santa Catarina (MAPA 1987). Com base no espaçamento entre plantas e da massa de tubérculos obteve-se o rendimento por hectare.

Os dados foram analisados estatisticamente por meio da análise de variância, seguida por comparação das médias por meio do teste de Tukey, $\mathrm{p} \leq 0,05$ por meio do programa SAS (SAS INSTITUTE 1996). Para os dados de massa nas diferentes classes de tubérculos foi realizada a transformação logarítmica antes da análise de variância.

\section{RESULTADOS E DISCUSSÃO}

\section{Rendimento de tubérculos}

A produtividade total de tubérculos foi sempre superior a $20 \mathrm{t} \mathrm{ha}^{-1}$ e não foi influenciada significativamente pelos tratamentos (Figura 2). Nos tratamentos que haviam recebido fosfato natural (T1, T2 e T3), independentemente da dose, as produtividades foram similares ao tratamento que havia recebido somente a cama de aviário (T4). Portanto, embora o fosfato natural Gafsa tenha um custo por unidade de $\mathrm{P}$ inferior a maioria das fontes solúveis de $\mathrm{P}$, não houve vantagem alguma do seu uso quando combinado com a cama de aviário. Um fator que deve estar relacionado à baixa resposta do fosfato natural Gafsa é o ciclo relativamente curto da cultura da batata (HOROWITZ \& MEURER 2004), não havendo tempo suficiente para que o fosfato natural pudesse ser solubilizado ao ponto de suprir a demanda das plantas por P. Além disso, espécies com o sistema radicular pouco desenvolvido, a exemplo da batata, podem apresentar baixa resposta ao uso de fosfato natural (MARWAHA 1989). Outro fator que pode explicar a baixa eficiência do fosfato natural é o fato de o fertilizante ter sido aplicado junto à linha de plantio, o que pode ter dificultado a dissolução do fertilizante (OLIVEIRA JUNIOR et al. 2008, FRANZINI et al. 2009). Embora os fosfatos sedimentares reativos, como o de Gafsa, apresentem maior solubilidade do que os fosfatos naturais de origem ígnea ou metamórfica, também podem apresentar baixa eficiência quando aplicados de modo localizado ao solo (CORRÊA et al. 2005). Por isso, a aplicação a lanço resulta em resposta superior à aplicação no sulco (OLIVEIRA JUNIOR et al. 2008), comprovando a necessidade de contato entre o solo e a rocha fosfática para aumentar a taxa de dissolução da rocha e, consequentemente, fornecer quantidades de P suficientes para o desenvolvimento das plantas (RAJAN et al. 1996, HOROWITZ \& MEURER 2004).

Entretanto, as produtividades sempre superiores a $23 \mathrm{t} \mathrm{ha}^{-1}$, independentemente de tratamento (Figura 2), sugerem que o uso de cama de aviário no plantio permitiu a obtenção de rendimentos satisfatórios, considerando-se que a média nacional de produtividade é de 27,7 t ha ${ }^{-1}$ (FAO 2015). LYNCH et al. (2008) aplicaram a dose de cama de aviário peletizada a fim de suprir $300 \mathrm{~kg} \mathrm{ha}^{-1}$ de $\mathrm{N}$ e observaram um incremento de até 7,0 $\mathrm{t} \mathrm{ha}^{-1}$ na produtividade de tubérculos. A cama de aviário por possuir uma baixa relação C:N facilita a degradação do composto, o que faz com que ela disponibilize rapidamente os nutrientes, principalmente o P. Além disso, a adição de material orgânico favorece a solubilização microbiana do fosfato (MOREIRA \& SIQUEIRA 2002), o que aumenta a disponibilidade de $\mathrm{P}$ às plantas. QUEIROZ et al. (2013), avaliando a resposta da batata a doses de adubo ( $\mathrm{N}-\mathrm{P}_{2} \mathrm{O}_{5}-\mathrm{K}_{2} \mathrm{O}$ - 4-14-8) obtiveram o máximo rendimento econômico com a dose de $3500 \mathrm{~kg} \mathrm{ha}^{-1}$, o que correspondeu a uma quantidade similar de $\mathrm{P}$ à utilizada neste estudo com a dose de $8 \mathrm{tha}^{-1}$ de cama de aviário. Entretanto, NAVA et al. (2007), em estudo realizado em solo com características similares ao do presente estudo, obtiveram resposta em termos de produção de tubérculos até a dose de $820 \mathrm{~kg} \mathrm{ha}^{-1}$ de $\mathrm{P}_{2} \mathrm{O}_{5}$, indicando que a cultura da batata é pouco eficiente em absorver P do solo (DECHASSA et al. 2003).

A incorporação do resíduo ao solo no sulco de plantio e a precipitação pluviométrica mensal sempre superior a $177 \mathrm{~mm}$ durante os meses de janeiro a março de 2010 (Figura 1) podem ter favorecido a decomposição do resíduo orgânico. Teores adequados de umidade e a incorporação da cama de aviário ao solo favorecem a disponibilização de nutrientes para as plantas se comparada à aplicação sobre a superfície do solo (ROGERI 2010).

A avaliação do rendimento por classes de tamanho de tubérculos também não mostrou qualquer diferença entre os tratamentos (Tabela 1). A maior 


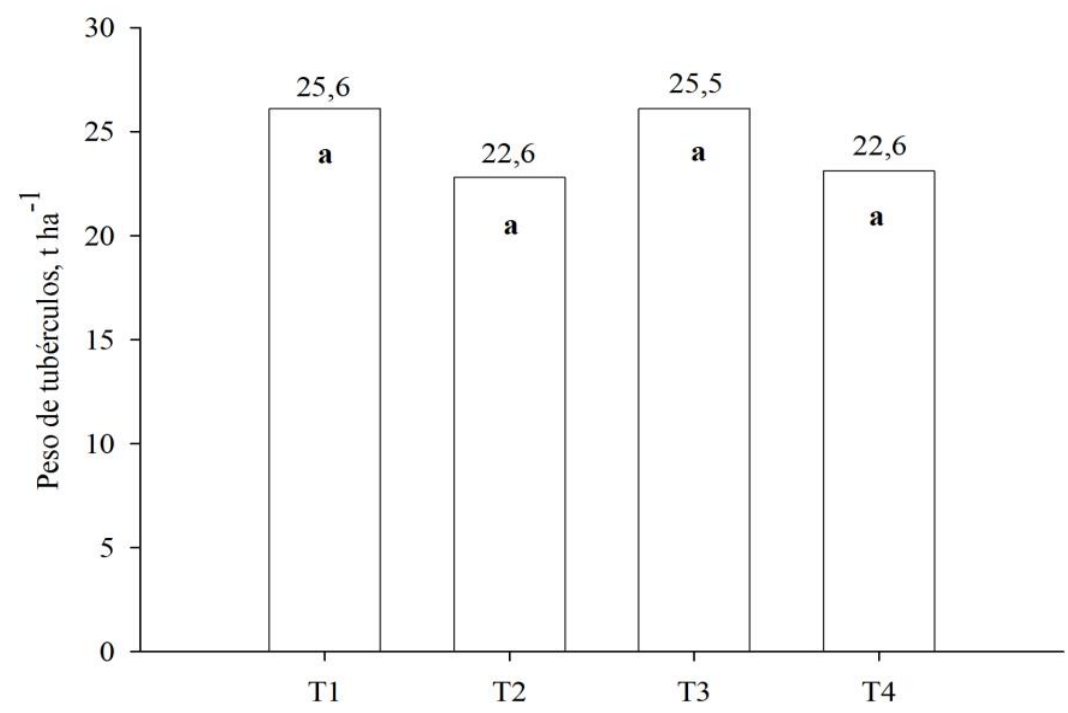

Figura 2 - Produtividade de tubérculos de batata $\left(\mathrm{t} \mathrm{ha}^{-1}\right)$, cultivar "catucha", em resposta a diferentes tratamentos contendo camas de aviário e fosfato natural Gafsa.

Médias seguidas pela mesma letra na coluna não diferem significativamente pelo teste de Tukey, $\mathrm{p} \leq 0,05$; $\mathrm{T} 1-4000 \mathrm{~kg} \mathrm{ha}^{-1}$ de fosfato natural Gafsa $+8 \mathrm{t} \mathrm{ha}^{-1}$ de cama de aviário; T2 - $2666 \mathrm{~kg} \mathrm{ha}^{-1}$ de fosfato natural Gafsa $+8 \mathrm{t} \mathrm{ha}^{-1}$ de cama de aviário; T3 $-1333 \mathrm{~kg} \mathrm{ha}^{-1}$ de fosfato natural Gafsa $+8 \mathrm{t} \mathrm{ha}^{-1}$ de cama de aviário; $\mathrm{T} 4$ - somente $8 \mathrm{t} \mathrm{ha}^{-1}$ de cama de aviário.

Figure 2 - Potato tuber yield ( $\left.\mathrm{ha} \mathrm{a}^{-1}\right)$, "catucha" cultivar in response to different treatments containing poultry litter and Gafsa rock phosphate.

Means followed by the same letter in the column do not differ significantly by Tukey test, $p \leq 0,05 ; T 1-4000 \mathrm{~kg}$ ha-1 of Gafsa rock phosphate $+8 \mathrm{tha}^{-1}$ de poultry litter; T2 - $2666 \mathrm{~kg} \mathrm{ha}^{-1}$ of Gafsa rock phosphate $+8 \mathrm{th} \mathrm{a}^{-1}$ of poultry litter; T3-1333 $\mathrm{kg} \mathrm{ha}^{-1}$ of Gafsa rock phosphate $+8 \mathrm{th} \mathrm{a}^{-1}$ of poultry litter; T4 $-8 \mathrm{th} \mathrm{a}^{-1}$ of poultry litter.

proporção de tubérculos ocorreu nas classes 4 e 5 (tubérculos grandes), que juntas e na média dos tratamentos representaram aproximadamente $80 \%$ da massa total de tubérculos. Estudos já realizados sobre o efeito da adubação fosfatada sobre o tamanho de tubérculos indicam uma relação positiva entre as doses de P aplicadas e a massa média de tubérculos (ROSEN et al. 2014, FERNANDES et al. 2015a e 2015b, FERNANDES et al. 2016), principalmente quando a fertilização é realizada em solos com baixos teores disponíveis de P. Em se tratando de produção de batata para consumo, este efeito é desejável, uma vez que aumenta o volume de tubérculos maiores, os quais são mais apreciados pelos consumidores.

\section{Composição mineral das folhas}

Não houve diferenças significativas entre os tratamentos em relação à concentração foliar para nenhum dos nutrientes avaliados (Tabela 2). Exceto para cálcio e fósforo, que tiveram suas concentrações abaixo do limite inferior da faixa de suficiência considerada adequada $\left(10-20 \mathrm{~g} \mathrm{~kg}^{-1}\right.$ e $2-5$ $\mathrm{g} \mathrm{kg}^{-1}$, respectivamente), para os demais nutrientes, as concentrações foliares foram consideradas adequadas (CQFS-RS/SC 2004). Independentemente do tratamento, a concentração de $\mathrm{P}$ atingida nas folhas foi de aproximadamente $1,0 \mathrm{~g} \mathrm{~kg}^{-1}$, a qual corresponde à metade do valor considerado suficiente para a cultura da batata, conforme recomendações da CQFS-RS/ SC (2004) para os estados do Rio Grande do Sul e Santa Catarina. Embora as plantas não apresentassem sintomas visuais de deficiência de $\mathrm{P}$ na parte aérea, os teores foliares de $\mathrm{P}$ sempre abaixo do limite inferior da faixa normal $\left(<2,0 \mathrm{~g} \mathrm{~kg}^{-1}\right)$, indicam que houve limitação no suprimento deste nutriente à cultura, o que possivelmente está associado à baixa contribuição fosfato natural Gafsa em disponibilizar P.

Uma medida que poderia ter gerado resultados diferentes dos encontrados no presente estudo teria sido a aplicação antecipada do fosfato natural em relação ao plantio da batata, bem como sua incorporação num volume maior de solo (a lanço), o que poderia aumentar a quantidade do $\mathrm{P}$ solubilizada pelo fertilizante (OLIVEIRA JUNIOR et al. 2008) $\mathrm{e}$, consequentemente, a quantidade do nutriente absorvida pelas plantas. Além disso, recomenda-se 
Tabela 1 - Classificação de tubérculos de batata por tamanho, cultivar "catucha", em resposta a diferentes tratamentos contendo camas de aviário e fosfato natural Gafsa.

Table 1 - Potato tubers classification by size, "catucha" cultivar in response to different treatments containing poultry litter and Gafsa rock phosphate.

\begin{tabular}{cccccc}
\hline \multirow{2}{*}{ Tratamento } & \multicolumn{5}{c}{ Classes de tubérculos } \\
\cline { 2 - 6 } & I & II & III & IV & V \\
\hline & $0,200 \mathrm{a}$ & $0,222 \mathrm{a}$ & $4,52 \mathrm{a}$ & $15,07 \mathrm{a}$ & $5,65 \mathrm{a}$ \\
T1 & $0,200 \mathrm{a}$ & $0,360 \mathrm{a}$ & $3,86 \mathrm{a}$ & $12,18 \mathrm{a}$ & $6,02 \mathrm{a}$ \\
T2 & $0,220 \mathrm{a}$ & $0,340 \mathrm{a}$ & $3,70 \mathrm{a}$ & $14,32 \mathrm{a}$ & $6,94 \mathrm{a}$ \\
T3 & $0,200 \mathrm{a}$ & $0,440 \mathrm{a}$ & $3,42 \mathrm{a}$ & $12,22 \mathrm{a}$ & $6,40 \mathrm{a}$ \\
T4 & 23,6 & 59,2 & 23,4 & 27,1 & 40,4
\end{tabular}

Médias seguidas pela mesma letra na coluna não diferem significativamente pelo teste de Tukey, $p \leq 0,05$; $\mathrm{T} 1-4000 \mathrm{~kg} \mathrm{ha}^{-1}$ de fosfato natural Gafsa $+8 \mathrm{tha}^{-1}$ de cama de aviário; T2 - $2666 \mathrm{~kg} \mathrm{ha}^{-1}$ de fosfato natural Gafsa $+8 \mathrm{tha}^{-1}$ de cama de aviário; T3 $-1333 \mathrm{~kg} \mathrm{ha}^{-1}$ de fosfato natural Gafsa $+8 \mathrm{t} \mathrm{ha}^{-1}$ de cama de aviário; $\mathrm{T} 4$ - somente $8 \mathrm{tha}^{-1}$ de cama de aviário.

Tabela 2 - Concentrações dos nutrientes nas folhas da cultura da batata, cultivar "catucha", em resposta a diferentes tratamentos contendo camas de aviário e fosfato natural Gafsa.

Table 2 - Concentration of nutrients in potato crop leaves, "catucha" cultivar in response to different treatments containing poultry litter and Gafsa rock phosphate.

\begin{tabular}{cccccccccc}
\hline Tratamento & $\mathrm{N}$ & $\mathrm{P}$ & $\mathrm{K}$ & $\mathrm{Ca}$ & $\mathrm{Mg}$ & $\mathrm{Fe}$ & $\mathrm{Mn}$ & $\mathrm{Zn}$ & $\mathrm{B}$ \\
\hline & $-----------------\mathrm{g} \mathrm{kg}^{-1}---------------$ & & $---------\mathrm{mg} \mathrm{kg}^{-1}---------$ \\
T1 & $40,1 \mathrm{a}$ & $0,99 \mathrm{a}$ & $73,0 \mathrm{a}$ & $7,78 \mathrm{a}$ & $3,40 \mathrm{a}$ & $70,1 \mathrm{a}$ & $168 \mathrm{a}$ & $22,9 \mathrm{a}$ & $25,3 \mathrm{a}$ \\
T2 & $41,1 \mathrm{a}$ & $1,08 \mathrm{a}$ & $76,3 \mathrm{a}$ & $7,30 \mathrm{a}$ & $3,30 \mathrm{a}$ & $64,6 \mathrm{a}$ & $153 \mathrm{a}$ & $20,4 \mathrm{a}$ & $26,6 \mathrm{a}$ \\
T3 & $39,1 \mathrm{a}$ & $0,96 \mathrm{a}$ & $73,1 \mathrm{a}$ & $6,94 \mathrm{a}$ & $3,28 \mathrm{a}$ & $60,3 \mathrm{a}$ & $143 \mathrm{a}$ & $19,6 \mathrm{a}$ & $25,6 \mathrm{a}$ \\
T4 & $40,3 \mathrm{a}$ & $0,93 \mathrm{a}$ & $73,2 \mathrm{a}$ & $7,72 \mathrm{a}$ & $3,36 \mathrm{a}$ & $67,3 \mathrm{a}$ & $152 \mathrm{a}$ & $21,5 \mathrm{a}$ & $27,3 \mathrm{a}$ \\
Média & 40,1 & 1,01 & 74,1 & 7,34 & 3,33 & 65,0 & 154 & 21,0 & 25,8 \\
Faixa adequada & $40-50$ & $2,0-5,0$ & $40-65$ & $10-20$ & $3,0-5,0$ & $50-100$ & $30-250$ & $20-60$ & $25-50$ \\
\hline CV (\%) & 4,6 & 7,9 & 6,3 & 11,3 & 11,4 & 13,6 & 13,7 & 11,5 & 14,6
\end{tabular}

Médias seguidas pela mesma letra na coluna não diferem significativamente pelo teste de Tukey, $\mathrm{p} \leq 0,05$; $\mathrm{T} 1-4000 \mathrm{~kg} \mathrm{ha}^{-1}$ de fosfato natural Gafsa $+8 \mathrm{tha}^{-1}$ de cama de aviário; T2 - $2666 \mathrm{~kg} \mathrm{ha}^{-1}$ de fosfato natural Gafsa $+8 \mathrm{tha}^{-1}$ de cama de aviário; T3 $-1333 \mathrm{~kg} \mathrm{ha}^{-1}$ de fosfato natural Gafsa $+8 \mathrm{t} \mathrm{ha}^{-1}$ de cama de aviário; $\mathrm{T} 4$ - somente $8 \mathrm{t} \mathrm{ha}^{-1}$ de cama de aviário.

a realização de outros estudos para avaliar o efeito residual do fosfato natural Gafsa aplicado em anos anteriores ao cultivo da batata. O maior tempo de reação do fosfato natural pode favorecer a dissolução da rocha fosfática (HOROWITZ \& MEURER 2004) e, consequentemente, a disponibilização do P para as plantas.

\section{CONCLUSÃO}

A aplicação de até $4 \mathrm{t} \mathrm{ha}^{-1}$ de fosfato natural Gafsa combinada com a dose de $8 \mathrm{t} \mathrm{ha}^{-1}$ de cama de aviário não influencia a produtividade de tubérculos e a composição mineral das folhas em um sistema orgânico de produção de batata consumo.

Independentemente do tratamento aplicado, as concentrações de $\mathrm{P}$ e de $\mathrm{Ca}$ nas folhas encontram-se abaixo do limite inferior da faixa de concentração considerada normal para a cultura da batata, indicando 
a limitação no suprimento destes nutrientes.

\section{REFERÊNCIAS}

CEPEA - Centro de Estudos Avançados em Economia Aplicada. 2016. Disponível em: http://cepea.esalq.usp. br/hfbrasil/edicoes/139/mat_capa.pdf. Acesso em: 22 jan. 2016.

CQFS-RS/SC - Comissão de Química e Fertilidade do Solo. 2004. Manual de adubação e de calagem para Estados do Rio Grande do Sul e de Santa Catarina. 10.ed. Porto Alegre: CQFS/SBCS. 400p.

CQFS-RS/SC - Comissão de Química e Fertilidade do Solo. 2016. Manual de calagem e adubação e para os estados do Rio Grande do Sul e de Santa Catarina; SBCS-NRS: Brasil, 11.ed. Santa Maria. 376p.

CORRÊA RM. et al. 2005. Gafsa rock phosphate and triple superphosphate for dry matter production and $\mathrm{P}$ uptake by corn. Scientia Agricola 62: 159-164.

DECHASSA N et al. 2003. Phosphorus efficiency of cabbage (Brassica oleraceae L. var. capitata), carrot (Daucus carota L.), and potato (Solanum tuberosum L.). Plant and Soil 250: 215-224.

ESPANHOL GL et al. 2007. Propriedades químicas e físicas do solo modificadas pelo manejo de plantas espontâneas e adubação orgânica em pomar de macieira. Revista de Ciências Agroveterinárias 6: 83-94.

FAO. FAOSTAT. 2015. Disponível em: http://faostat3.fao. org/browse/Q/QC/E. Acesso em: 22 jan. 2016.

FERNANDES AM et al. 2015b. Qualidade de tubérculos de batata da cultivar 'Atlantic' afetada pela adubação fosfatada. Ciência Rural 45: 1401-1407.

FERNANDES AM et al. 2015a. Effect of phosphorus nutrition on quality of fresh tuber of potato cultivars. Bragantia 74: 102-109.

FERNANDES AM et al. 2016. Influência do fósforo na qualidade e produtividade de tubérculos de cultivares de batata de duplo propósito. Horticultura Brasileira 34: 346355.

FRANZINI VI et al. 2009. Eficiência de fosfato natural reativo aplicado em misturas com superfosfato triplo em milho e soja. Pesquisa Agropecuária Brasileira 44: 10921099.

HOROWITZ N \& MEURER EJ. 2003. Eficiência de dois fosfatos naturais farelados em função do tamanho da partícula. Ciência Rural 33: 41-47.

HOROWITZ N \& MEURER EJ. 2004. Eficiência agronômica dos fosfatos naturais. In: YAMADA T \& ABDALLA SRS. (Eds.). Fósforo na agricultura brasileira. Piracicaba: Potafos. p.665-687.

LUZ JMQ et al. 2013. Influence of phosphate fertilization on phosphorus levels in foliage and tuber yield of the potato cv. Ágata. Semina: Ciências Agrárias 34: 649-656.

LYNCH DH et al. 2008. Organic amendment effects on tuber yield, plant $\mathrm{N}$ uptake and soil mineral $\mathrm{N}$ under organic potato production. Renewable Agriculture and Food Systems 23: 250-259.

MAPA - Ministério da Agricultura, Pecuária e Abastecimento. 1987. Portaria $\mathrm{N}^{\circ} 154$, de 23 de julho de 1987. Disponível em http://editoramagister.com/ doc_6225687_PORTARIA_N_154_DE_23_DE_JULHO_ DE_1987.aspx. Acesso em: 10 mar. 2016.

MARWAHA BC. 1989. Rock phosphate holds the key to productivity in acid soils: a review. Fertilizer New 34: 2329.

MOREIRA FMS \& SIQUEIRA JO. 2002. Microbiologia e bioquímica do solo. Lavras: UFLA. 626p.

NAVA G et al. 2007. Produção de tubérculos de batatasemente em função das adubações nitrogenada, fosfatada e potássica. Horticultura Brasileira 25: 365-370.

OLIVEIRA JUNIOR A et al. 2008. Eficiência agronômica de fosfato natural reativo na cultura da soja. Pesquisa Agropecuária Brasileira 43: 623-631.

QUEIROZ LRM et al. 2013. Adubação NPK e tamanho de batata-semente no crescimento, produtividade e rentabilidade de plantas de batata. Horticultura Brasileira 31: 119-127.

RAJAN SSS et al. 1996. Phosphate rocks for direct application to soils. Advances in Agronomy 57: 77-159.

ROGERI DA. 2010. Suprimento e perdas de N no solo decorrentes da adição de cama de aves. Dissertação (Mestrado em Manejo do Solo). Lages: UDESC. 98p.

ROSEN CJ et al. 2014. Optimizing Phosphorus Fertilizer Management in Potato Production. American Journal of Potato Research 91: 145-160.

SANTOS et al. 2013. Sistema brasileiro de classificação de solos. 3.ed. rev. e ampl. Brasília: EMBRAPA. 353p.

SAS INSTITUTE. 1996. SAS, versão 6.12. Cary, NC: SAS Institute INC. CD-ROM.

SILVA TO et al. 2007. Adubação orgânica da batata com esterco e/ou Crotalaria juncea. I - Produtividade vegetal e estoque de nutrientes no solo em longo prazo. Revista Brasileira de Ciência do Solo 31: 39-49.

SIQUEIRA JO. et al. 2004. O papel dos microrganismos na disponibilização e aquisição de fósforo pelas plantas. In: YAMADA T \& ABDALLA SRS. (Eds.) Fósforo na agricultura brasileira. Piracicaba: Potafos. p.117-156.

VALADÃO FCA et al. 2011. Variação nos atributos do solo em sistemas de manejo com adição de cama de frango. Revista Brasileira de Ciência do Solo 35: 2073-2082. 